\title{
Characteristics of Electronic Integrated System and Trust in the Provider of Service
}

\author{
Ibrahim Abunadi \\ Collage of Computer and \\ Information Sciences, \\ Prince Sultan University \\ 11586 Riyadh, Saudi Arabia
}

\begin{abstract}
Saudi Arabia has one of the world's largest vehicle accident death rates. To overcome this, an electronic integrated system was initiated, which contains many components, including surveillance and penalizing systems; however, this system experienced what could be called an extreme system rejection in which some components were hacked, vandalized or even destroyed. To gain an understanding of this issue, the characteristics of the system were studied by modelling them using different theoretical perspectives. In addition, inferential statistics and a branch of data mining (sentiment analysis) were utilized to acquire a clearer insight into the causes. The results of this study include strategic and technological recommendations that could be of use for developers, researchers and decision makers for developing, studying or implementing similar systems.
\end{abstract}

\section{Keywords}

System characteristics, Data mining, Violation systems.

\section{INTRODUCTION}

The kingdom of Saudi Arabia (KSA) has one of the highest world mortality rates caused by road accidents. This shows that there are serious issues that need to be addressed regarding the driving behaviors of individuals. Many traditional methods were used to reduce the damage caused in human and economic capital in the country without a tangible impact on the status quo. Thus, an integrated electronic system (Saher) was introduced in 2009 to monitor and automatically penalize those who violate traffic laws; however, this system was challenged by many contemptuous reactions from drivers and was not smoothly implemented or accepted. Many citizens doubted the performance and intentions of the provider of the service (the private sector maintaining the system temporarily) due to various reasons that will be explained further. This temporary endeavor by the company has led to what can be called an extreme case of system rejection by residents. System rejection has caused many losses for the provider of service in which the system or its components were sabotaged, damaged, or destroyed. [5, $27,30,36,55]$.

Many organizations and providers of service seek to achieve higher levels of trust with the societies in which they serve. Trust is considered an important factor in increasing the exchange in relationships between organizations and citizens $[21,53]$. Trust also leads to better acceptance of services and products provided by these organizations and higher profits or reliance. Despite its importance, studies on KSA from this perspective are insufficient. Thus, this study aims to study trust in the provider of services in KSA and how the system and website characteristics lead to better trust. The importance of trust in this case is that it allows citizens to accept being vulnerable to the provider of service. This is necessary, as the conducted transaction in most cases cannot be completed without sharing private information [14]. Trust in the case of services provided through the Internet is more imperative considering the dynamic nature and uncertainty present in the Internet environment [2].

Secure Electronic Transactions (SET) was considered a technological advancement that could lead to renewing the relationship between governments and citizens [3, 48, 64]. SET is one of the solutions for the improvement of services and communication between citizens and the government. Secured seamless services and two-way communication between citizens and their government would ultimately increase trust in government agencies [48, 64]. One of the provided services that is an interesting case and has caused higher levels of distrust in the provider of service for the citizens is "Saher." The Arabic word "saher" means "watchful" in English, indicating that this traffic system is for watching over the safety of the road drivers [6]. This system was considered a necessity after statistics have shown that road accidents are the major cause of death in KSA [27]. Saher is an automated electronic system that uses digital cameras to monitor traffic violations $[6,27]$.

According to Alhindi and Albawardy [6], Saher is not trusted as a system that reduces accidents. Their study indicates that it is perceived as way to collect fines since a private sector organization maintains Saher to gain profits from traffic violators. This public and private sector alliance is considered an acceptable governmental practice; however, it created an extreme case of technology and system rejection for Saudi drivers $[6,55]$. Many incidents have been reported in which the system components have been attacked, hacked, or destroyed, including operators, the SET system, or a road camera [55]. Several participants in the conducted survey expressed their dissatisfaction with the payment procedure of the traffic system. One of the reasons for this was that residents were not satisfied that a private sector organization actually profits from traffic violation payments $[12,55]$. The "businessman" is used throughout this paper to refer to the owner of the company that maintains the Saher system. To determine that the discontent with Saher originates from this PPP (Public and Private Partnership), the mentioning of the word "Saher" in twitter was studied. It was found that between the period of 200 days, "Saher" was mentioned 450 times, and the business man's name was mentioned 411 times. All of these tweets had negative indications and complained about Saher or about how the "businessman" is gaining profit from this system. To detect and classify all of these tweets, the twitter data mining Twitterfall tool was used in addition to twitter search engine [44]. 


\section{THE AUTOMATED TRAFFIC VIOLATION SYSTEM (SAHER)}

Many countries around the world have adopted intelligent transportation law enforcement systems to reduce car accidents and to increase the awareness of drivers of the dangers of the roads [6]. The Arabic word "saher" means "watchful" in this context. Saher is an Automated Traffic Violations Administering and Monitoring System (ATVAMS). This system was introduced in major cities and rural areas out of necessity. To achieve the purpose of reducing accidents in the most financially effective matter, government agencies contracted a reputable private sector company $[6,36]$. This company was responsible for building and operating the Saher system in a predetermined period of time and then transferring it to the public sector. The company accepted the contract on the condition of gaining a profit from the system. This condition was known to the public, and it was one of the causes of criticism [6, 27, 55]. The implementation of this system is justified by the high rates of car accidents within the KSA. The car accident fatality rates are one of the highest in the world, and it has been reported that car accidents are the second leading cause for death in the kingdom [4, 5, 30]. Saher system components include cameras, monitoring systems, a banking payment system and an SET website $[36,55]$. The main functions of this system include a traffic management system, vehicle locating, license plate recognition and a law enforcement payment system. The Saher Electronic Integrated System was developed to monitor the traffic flow for different types of violations. Infringements are issued automatically based on the license plate number, and the violator is notified through the registered mobile phone or other contact details $[12,36]$. Information flows are automatically utilized by traffic lights and road signs, which facilitate traffic flow [36].

\section{TRUST IN THE PROVIDER OF SERVICE (TIPS)}

Building trust between the providers of the service and the users is necessary to facilitate the adoption of the service. The adoption of the electronic service in this context includes accepting the use of the service, sharing information with the provider of the service, and continuing to use the service from the online channel $[1,7,64]$. Trust has been emphasized in egovernment research as one of the most salient factors in the development and adoption of government provided e-services [47].

Trust in the provider (or the government in this case) has not been discussed adequately as the core dependent factor in the comparison of the intention of usage. E-government literature has focused on considering trust to be an antecedent of other factors, especially the acceptance and adoption, or other factors, such as risk and security perceptions, attitudes, perceived behavioral control, service quality, information quality, and system quality $[1,9,33,52,53,66]$.

Rotter [58] defined interpersonal trust as "an expectancy held by an individual or a group that the word, promise, verbal or written statement of another individual or group can be relied on" (p. 444). Barney and Hansen [13] defined trust as "the mutual confidence that no party to an exchange will exploit another's vulnerabilities" (p. 176). On the other hand, a service is defined as "any act of performance that one party offer to another" [42]. The literature has distinguished between trust in the provider of service and trust in the system (e.g., website) in which the service is provided [53]. Liao et al. [45] mentioned that trust in the website means that the medium in which the service is conducted (the Internet) is robust, secure, and reliable. Trust in the provider of service is defined as perceptions of "confidentiality, honesty, integrity and high ethical standards" [22]. Trust in the provider of service is established through a process in which the citizens (or customers) build their trust based on the conducted transactions [15]. Trust in the government as a provider of service has been defined by Miller and Listhaug [49] as "whether or not political authorities and institutions are performing in accordance with normative expectations held by the public." A study has indicated that trust in the provider of service is more important to the acceptance of the service than the platform that the service is provided through [52]. Trust in the provider of service is defined in this study as its ability to conduct the required transactions in a trustworthy, faithful, and benevolent manner.

\section{CHARACTERISTICS OF SAHER SYSTEM (PREDICTORS OF TIPS)}

Considering that the Saher system is a clear case of an innovation in KSA, the aspects of innovation are required to be studied at the same time to acquire an accurate picture of this case [54, 65]. One of the highly cited and well-regarded theories of information systems explaining the adoption of innovation is Rogers' theory of diffusion of innovation [35, 57, 60]. There are two stages that explain the adoption process: pre-adoption and post-adoption. Since Saher was introduced in 2009, the individuals within the society have been familiar with using it, discussing it, and criticizing it in the media and in public [55], which shows that this system is currently considered to be in the post-adoption stage for individuals and society. The post-adoption stage entails whether the citizen uses this system or rejects it [57]. Based on Rogers' theory, Moore and Benbasat [51] the theory of perceived characteristics of information technology innovation was developed. Eight constructs are used to model user perceptions of innovated technological systems. The following constructs were established in Moore and Benbasat's (1991) theory of perceived characteristics of an innovation: relative advantage, compatibility, ease of use, result demonstrability, image, visibility, observability, and trialability. These characteristics of technology innovation provide a rich explanation of user interaction with technology and have been applied in different settings [25, 26, 43]. In addition, Moore and Benbasat's development of the theory and instrument operationalization was rigorous and technologically focused [51, 63, 65]. Consequently, the research model is based on their theory and extended by including trust in the provider of the service and the Internet.

Kapoor et al. [37] have conducted a study about a payment system in India that is similar to Saher and found that relative advantage, compatibility, complexity, and visibility are the most important factors; however, this study is slightly different from that of Kapoor et al. [37] since their study focuses on a mobile banking system that has a general use rather than Saher, which focuses on traffic violations. The most similar study to this paper was conducted in Kuwait using the Unified Theory of Acceptance and Use of Technology. Although the violation system used in the mentioned study is similar to this study, the focus and the grounding theory are different. In addition, the dependent construct used was adoption, while TIPS is considered the dependent construct in this study [40].

Relative advantage is expected to significantly contribute towards TIPS. It is defined as the advantage that the technology offers in comparison with other previous methods 
[51]. Previous traffic violations were manually handled by police officers in which if an offence were observed, the driver would be stopped and a violation would be written. The driver then goes to a bank or ATM (Auto Telling Machine) to pay for the violation [36, 55]; however, currently, traffic violations are recorded by cameras, and payment can be conducted online. There is no direct human intervention [36, 55]. The relative advantage originated in Rogers' (2003) research and has been contextualized to a technology application by Moore and Benbasat (1991). No other study has been found to apply a relative advantage on a traffic violation system. Most studies have focused on e-government systems, which is a relatively different case compared with this study [26]. The corresponding hypothesis is as follows:

H1: A higher level of relative advantage will be positively correlated with trust in the provider of service.

Compatibility is a factor that has been discussed widely in information systems in several contexts that are different from this study. Compatibility is defined as the degree to which a technological innovation is consistent with the user's needs, values, and previous experiences. In this research, the context of the compatibility of the Saher system could consider previous methods of infringement payments that citizens used, such as using an ATM (Auto Teller Machines) or conducting payment by physically visiting a bank. As the current system utilizes e-banking systems, it is expected that Saher would meet citizens' needs, and a higher compatibility would lead to higher levels of trust in the provider of service [36, 55]. Therefore, the following is hypothesized:

H2: A higher level of compatibility will be positively correlated with trust in the provider of service.

Complexity was originally found in Rogers' (2003) research and has been replaced by ease of use in Moore and Benbasat's (1991) paper; however, due to the negative nature of the violation system, it would more be more relevant to include a factor that has a negative connotation, especially when usage of the system is involved because users would be paying fines when using the system [40]. Complexity is defined as the degree to which a technological innovation is considered difficult to comprehend and use [51]. Therefore, it is expected that the more complex the system is for the citizens, the lower level of trust in the provider of service. The following is hypothesized:

H3: A higher level of complexity will be negatively correlated with trust in the service provider.

Result demonstrability is not found in Rogers' work [56, 57] and was incepted in Moore and Benbasat [51]. Rogers' [56] observability was divided by Moore and Benbasat [51] into result demonstrability and trialability. Result demonstrability is a factor that is rarely discussed in information systems research, unlike relative advantage, compatibility, and complexity $[43,65]$. Result demonstrability refers to the degree to which technological innovation results are observable and communicable by others [51]. The Saher system's effects and results have been observable by the media and society, and its effects have been widely discussed in social media, especially twitter [36]. This communicability is important for this case as many citizens prefer to avoid Saher cameras knowing their location and/or a duplication of the fines when payment is not made in a timely manner. Many Saher legislations have been affected by the ongoing and continuing discussion regarding Saher's influences on social media $[6,12,36]$. In addition, one of the most essential results of the Saher system should be a lower number of car accidents. If this occurred or was at least perceived, it would lead to higher levels of trust in the provider of service. Thus, the following is hypothesized:

H4: A higher level of result demonstrability will be positively correlated with trust in the provider of service.

Trialability and images were not investigated in this work. Trialability refers to whether a technological innovation is available for testing before actually being adopted. Since the Saher system is enforced and was not available on a trial basis, it was not included in this research. An image construct is defined as whether the usage of technology could enhance the user's self-image by those who surround her/him [51]. Since Saher is a violation system, its usage denotes that the user must pay for an infringement for breaking the traffic laws, and this would not enhance someone's image but would likely undermine it by showing a lack of driving competency [28]. Thus, the image construct was not included in this paper.

Visibility refers to the degree to which a technological innovation is visible by others [51]. This construct has rarely been used in information systems research [59]. Saher cameras are the visible part of this system, but sometimes it is hidden on roads and streets. There has not been a visible policy in this regard. Hiding cameras has induced considerable criticism on social networks in $\operatorname{KSA}[6,36,55]$. Thus, it is expected that this factor would play an important role in increasing trust in the provider of service when Saher cameras are visible to drivers. Therefore, the following is hypothesized:

H5: A higher level of visibility will be positively correlated with trust in the provider of service.

The final factor studied is considered an extension of Moore and Benbasat [51]'s theory and a considerable addition to this study, which is trust in the Internet. Trust in the Internet has been widely cited and found influential in e-government, ecommerce, and e-banking studies $[10,21,32]$. This construct is expected to play a significant role in this study because trust in the medium in which the infringement payment is conducted would lead to higher levels of trust in the provider of service. Provided security and privacy measures through the Internet would lead to higher levels of trust in the provider of service when this service is actually provided through the Internet [53]. The corresponding hypothesis for this construct is as follows:

H6: A higher level of trust in Internet will be positively correlated with trust in the provider of service.

The final research model with all hypothesized relations is shown in figure 1 . 


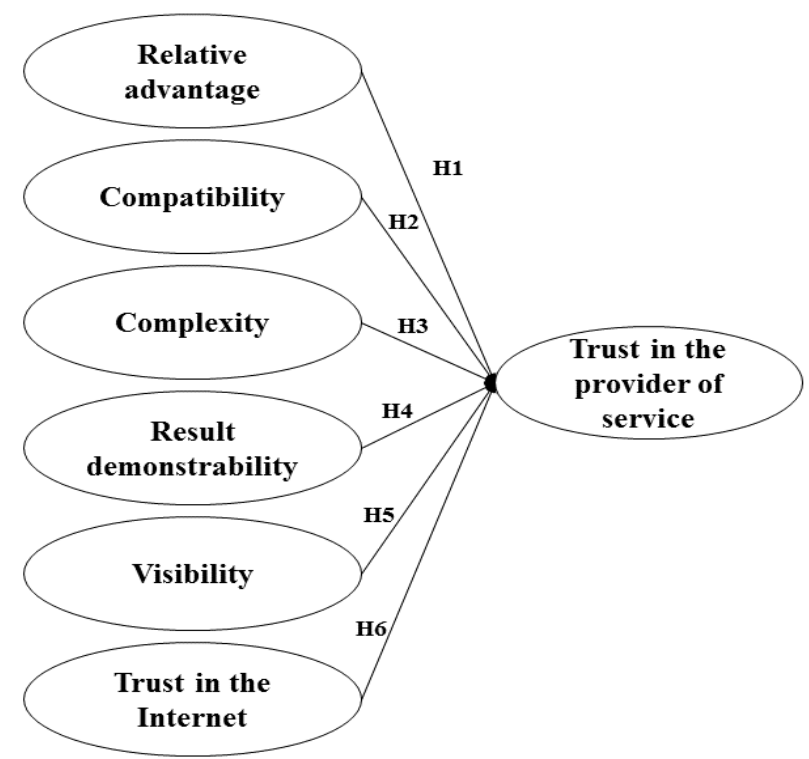

Fig 1: Research model

\section{METHOD}

All residents in KSA are subject to interact with the Saher system and therefore can be considered within the sample frame. Using multiple channels of contact, 837 participants were surveyed. Structural Equation Modeling was applied to assess the research model using AMOS 19.0 (Analysis of a Moment Structures). This approach was used to test the independent (trust in the service provider) construct and the dependent constructs (relative advantage, compatibility, complexity, result demonstrability, visibility, and trust in the Internet).

\subsection{Data Collection}

A pool of items were collected from previous studies and then reworded to suit this study, forming an initial instrument [18, 51]. To ensure content validity, this instrument was reviewed by academics who specialize in the field of information systems for the assessment of wording and the questionnaire design. Based on the feedback, changes to the instrument design and item wording were conducted for the sake of clarifying and simplifying participation in the study. The resulting instrument was translated using a professional translator and then sent to experts to assure the accuracy of the translation. Authoritative and widely cited references for instrument crafting and distribution were used as guidelines for this study $[11,16,17,20,23,31,67]$.

The data was collected via email. Publicly available email groups were used as a channel for distributing the surveys. To reduce any biases that may result from method bias, only email groups that did not focus on a specific topic were used [67].

\section{ANALYSIS}

Structural Equation Modelling (SEM) was used to assess the research model of this study and to test the hypothesized relations using AMOS version 19.0. SEM is considered a powerful covariance-based second generation statistical analysis tool, which consists of the measurement and structural models [16]. A Confirmatory Factor Analysis (CFA) was used to assess the measurement model in terms of reliability and validity. On the other hand, the structural model was used to assess the hypothesized relations between the constructs in the study [17].

\subsection{Normality and Multicollinearity}

One of the most important conditions for running a covariance-based SEM is to assure that normality and multicollinearity do not exist in the sample [31]. According to Curran et al. [24], an item skewness and kurtosis lower than 2 and 7 , respectively, are acceptable for the use of a covariance based analysis. The CFA of the model showed that all items had a skewness and kurtosis lower than the threshold. On the other hand, multicollinearity would be a concern if a high correlation exists between independent constructs. All constructs had correlations lower than the cut-off value, (0.85) which was suggested by Kline [41]. Both of these results enabled establishing the accuracy of the SEM analysis conducted in this study.

\subsection{Measurement Model}

The measurement model via CFA is used to assure that the proposed theoretical constructs provides sufficient validity and reliability [17]. AMOS utilizes different estimates to enable the assessment of the proposed CFA model, which includes: Goodness of Fit Index (GFI), Comparative of Fit Index (CFI), Adjusted Goodness of Fit Index (AGFI), Root Mean Square Error of Approximation and (RMSEA) Standardized Root Mean Square Residual (SRMR). GFI, CFI and AGFI $>0.90$ indicates a good fit, while RMSEA and SRMR $<0.05$ and $\chi^{2 /(d f)}<3$ also shows a good fit of the model to the data $[17,29,31]$. The CFA results were as follows: $\chi^{2} /(\mathrm{df})=1.72$, GFI $=0.95$, AGFI $=0.93$, CFI $=0.93$, RMSEA $=0.03$ and SRMR $=0.04$, showing that the model has a good fit.

Table 1. Measurement model validity.

\begin{tabular}{|l|l|l|l|l|}
\hline & CR & AVE & MSV & ASV \\
\hline REDM & 0.73 & 0.58 & 0.24 & 0.12 \\
\hline READ & 0.95 & 0.78 & 0.86 & 0.25 \\
\hline COMP & 0.93 & 0.77 & 0.86 & 0.24 \\
\hline COMX & 0.70 & 0.51 & 0.25 & 0.12 \\
\hline VISA & 0.70 & 0.50 & 0.14 & 0.04 \\
\hline TIIN & 0.92 & 0.79 & 0.15 & 0.08 \\
\hline TISP & 0.94 & 0.80 & 0.15 & 0.08 \\
\hline
\end{tabular}

Composite Reliability (CR), Average Variance Explained (AVE), and Cronbach's $\alpha$ were used to assess the reliability and internal consistency of all item-to-construct relations. A $\mathrm{CR}$ and AVE above than 7.0 and .05, respectively, indicates reliability and internal consistency for constructs. Table 1 shows that all reliability conditions were valid and that the model could be considered reliable for further analysis [31].

Table 2. Factor loading for all items.

\begin{tabular}{|l|l|l|}
\hline Construct & Items & Loading \\
\hline Relative Advantage & READ5 & 0.87 \\
\cline { 2 - 3 } & READ4 & 0.91 \\
\cline { 2 - 3 } & READ3 & 0.88 \\
\cline { 2 - 3 } & READ2 & 0.90 \\
\cline { 2 - 3 } & READ1 & 0.86 \\
\hline Compatibility & COMP4 & 0.84 \\
\cline { 2 - 3 } & COMP3 & 0.91 \\
\cline { 2 - 3 } & COMP2 & 0.84 \\
\cline { 2 - 3 } & COMP1 & 0.90 \\
\hline Complexity & COMX4 & 0.70 \\
\cline { 2 - 3 } & COMX2 & 0.80 \\
\hline Result Demonstrability & REDM2 & 0.86 \\
\cline { 2 - 3 } & REDM1 & 0.70 \\
\hline Visibility & VISA1 & 0.76 \\
\cline { 2 - 3 } & VISA2 & 0.70 \\
\hline
\end{tabular}




\begin{tabular}{|l|l|l|}
\hline Trust in the Internet & TIIN3 & 0.91 \\
\cline { 2 - 3 } & TIIN2 & 0.89 \\
\cline { 2 - 3 } & TIIN1 & 0.86 \\
\hline Trust in the Government & TISP4 & 0.84 \\
\cline { 2 - 3 } & TISP3 & 0.94 \\
\cline { 2 - 3 } & TISP2 & 0.93 \\
\cline { 2 - 3 } & TISP1 & 0.86 \\
\hline
\end{tabular}

The evaluation of the convergent and discriminant validity was conducted by investigating the following: AVE, Maximum Shared Variance (MSV), and Average Shared Variance (ASV). An MSV and ASV lower than the AVE would indicate validity, which is the case shown in Table 1. The conducted assessments show that the measurement model is suitable for structural assessment [11, 31]. An additional condition for convergent validity is a standardized regression weight where loading above 0.7 satisfies that condition [31]. The items COMX1, COMX3, REDM3, and REDM4 loadings were lower than 0.7 and therefore were excluded from further analysis. Table 2 shows that all items satisfy this convergent validity condition for all constructs. Therefore, a structural model could be estimated.

\subsection{Structural Model}

The structural model is used to assess the hypothesized relations between the constructs, which was conducted using AMOS [17]. Before further investigation could be conducted, the structural model indices were used to determine that the data was suitable for hypothesis assessment [31]. The model's indices showed a good fit: $\chi^{2} /(\mathrm{df})=2.48$, GFI $=0.92$, AGFI $=0.90$, CFI $=0.90$, RMSEA $=0.04$, and SRMR $=0.04$. In addition to the fit indices, the standardized path coefficients and significance and explained variance or $\mathrm{R}^{2}$ were used. These estimated values showed that all hypotheses were significant in explaining the dependent construct. The $\mathrm{R}^{2}$ showed that the model had an explanation power of $30 \%$ for trust in the provider of service for the independent constructs, which were relative advantage, compatibility, complexity, result demonstrability, visibility, and trust in the Internet. Table 3 below shows that all hypotheses were supported and that all constructs significantly impacted the dependent construct. To add an extra layer of explanation to the quantitative data, opinion mining was used and is discussed in the following section.

Table 3. Path results.

\begin{tabular}{|l|l|l|}
\hline Hypothesis & $\begin{array}{l}\text { Standardized } \\
\text { coefficient }\end{array}$ & Result \\
\hline H1 (READ $\rightarrow$ TIPS) & $0.47 * * *$ & Supported \\
\hline H2 (COMP $\rightarrow$ TIPS) & $-0.42 * * *$ & Supported \\
\hline H3 (COMX $\rightarrow$ TIPS) & $-0.22 * * *$ & Supported \\
\hline H4 (REDM $\rightarrow$ TIPS) & $0.11 * * *$ & Supported \\
\hline H5 (VISA $\rightarrow$ TIPS) & $0.20 * * *$ & Supported \\
\hline H6 (TIIN $\rightarrow$ TIPS) & $0.24 * * *$ & Supported \\
\hline
\end{tabular}

\section{OPINION MINING}

Opinion mining, or a sentimental analysis, is a form of data mining by collecting corpus or online data and then classifying it to find opinion polarity in the data [46, 62]. Twitterfall and twitter search engines were used to collect data from twitter, and the opinions were classified as positive, neutral, and negative based on the keywords used in the Arabic Saher hashtag. Phrases that mentioned Saher's original purpose; to save lives and reduce number of accidents, or positively mentioned the company running Saher were considered positive opinions. Neutral tweets were classified if they contained phrases that only presented facts or general information about Saher without positive or negative connotations.

Twitter is considered as a social network that enables its users to create micro-blogs where only 140 characters are allowed per message or "tweet". Twitter purpose is unlike other social networks where direct interaction between users is their main theme. Twitter main functions enhances spreading of news or personal information [62]. Each user has followers where they receive her/his tweets and updates through their timeline. Twitter users can in addition to tweeting, "retweet", "reply" and "favor" a tweet. Retweeting is a form forwarding the message to other followers. Replying a tweet is a public direct interaction with the original tweet sender. When a user "favors" a tweet she/he usually keep it in their profile for her/his reference or others. Another innovative feature of twitter is hashtagging, where a user can search and write on a given topic by inserting a "\#" in front of the topic word. This feature creates collaboration effectiveness where any user around can write about a specific topic [61, 62].

From the collected data, tweets were considered negative if they mentioned the financial impact of Saher on employees' income, negative comments regarding the company managing Saher, negative comments towards the 'businessman,' or methods to illegally avoid being detected by Saher cameras. Discussions about Saher were mostly negative or sarcastic of the system and how it is affecting the income of the violator. On the other hand, Positive tweets were defending the 'businessman' indicating that this system is only induced to reduce the total number of accidents in the country. The neutral tweets only presented some facts about Saher such as updates about the system or statistics. After all tweets were classified the number of each classification type were counted and the Table 4 shows resulting opinion mining statistics.

Table 4: Amalgamated statistics

\begin{tabular}{|l|l|l|l|}
\hline Classification & Positive & Negative & Neutral \\
\hline Tweet & 16 & 411 & 23 \\
\hline Reply & 1 & 54 & 1 \\
\hline Retweet & 1728 & 8633 & 1588 \\
\hline Favorite & 26 & 636 & 57 \\
\hline
\end{tabular}

Higher levels of interactions (reply, retweet, and favor) for the positive and negative opinions on Saher show polarity of opinions on this subject. The total number of interactions with the subject within only 6 and half months is 13,158 , which is considered a large number. What is noticeable is the high number (427) of mentioning the 'business' man within all tweets, which indicates his direct involvement in shaping the opinions of the participants. It can be stated that about $95 \%$ of the comments were negative, also showing that having a private sector running such a project would lead to negative sentiments. Figure 2 shows the clear difference between opinions and how large negative opinions soars in comparison to neutral and positive. In addition, the difference in terms of interaction, is obviously visible towards retweet which shows high reciprocation and endorsement towards negative opinions on Saher. Retweeting and favoring these tweens indicate that these negative messages reached and are endorsed by larger number of audience. 




Fig 2: Opinion classification statics

\section{DISCUSSION}

Research that focuses on the impact of technology characteristics on the trust of the provider of service is lacking, especially from the perspective that technology is a violation system. Thus, this study has achieved its purpose by investigating the effect of technology characteristics on the trust of the provider of service. To do so, data was collected and analyzed, and hypothesized relations were confirmed. In addition, opinion mining was used to support findings and to offer an additional explanation for why citizens would have negative opinions towards the company providing Saher. Microblogging about Saher using Twitter or tweets was considered a source of information for analysis for pointing out positive, neutral, or negative sentiments towards Saher and the company maintaining it. It was found that many citizens disliked that profits were collected from their traffic violations by a private company. Overall, after both sources of data were analyzed, it was shown that there are negative sentiments towards the private company maintaining Saher.

The SEM analysis showed that the strongest path relation (standardized coefficient) was found between relative advantage (0.47) and trust in the provider of service, followed by compatibility (0.42), trust in the internet $(0.24)$, complexity $(-0.22)$, visibility $(0.20)$, and result demonstrability $(0.11)$. The relative advantage finding shows that providing an electronic means of payment for traffic violations is preferable, and providing this technology would lead to higher levels of trust in the provider of service. Since relative advantage had the highest impact on trust in the provider of service, the importance of electronic payment technology for traffic violations is important in increasing trust. The successful implementation of this technology shows the competence of the provider of service, and citizens would trust their capabilities. This finding supports other findings found in research that has investigated the impact of relative advantage on the adoption of different technologies, such as cloud services, e-government, or e-payments [26, 37, 54]; however, the hypothesized relation between relative advantage and trust in the provider of service was not found in the literature.

Compatibility had the second strongest impact on the trust of the provider of service, as was indicated by the SEM analysis.
Saher violation payments could be paid using ATMS or ebanking systems, which many citizens are familiar with [8]. This added to the compatibility in terms of familiarity in handling Saher violation payments provided by the private company. Since safeness of the roads is an absolute necessity and Saher promises to provide that, this should add some compatibility of the system with the citizens' values and needs.

The third construct with regards to its impact on the trust of the provider of service was trust in the Internet. As previously hypothesized, trusting the security and privacy of the medium in which financial dealings are being conducted to pay for infringements is essential. This study is congruent with other studies, which found that the construct trust in the Internet had a significant impact on the independent construct [10, 19, 47].

The complexity of the ATVAMS has shown a negative influence on trust of the provider of service. The negative direction of the influence was reasonable since paying traffic violations should be as simple as possible when someone who has conducted a violation would already dislike paying the infringement, and complexity in the violation payment system would only increase dissatisfaction with the provider of service, leading to less trust $[8,40]$. This significant negative finding is consistent with the literature; however, it is consistent with the adoption of a technology construct [19, 59].

Complexity was directly followed by the visibility construct in terms of its influence on the provider of service. This result shows that an improved visibility of Saher detection technologies, including cameras, would lead to better trust in the provider of service. This finding is congruent with the opinion mining analysis in which many citizens complained that Saher cameras should be visible to everyone and signs should indicate its location. Result demonstrability had the lowest significant effect on trust in the provider of service. The opinion mining analysis showed that Saher's financial impact on the income of citizens is widely discussed. Other positive discussions about Saher were about its influence in reducing car accidents. Higher levels of trust in the provider of service could occur if the actual positive results of Saher are evident to citizens. Visibility and result demonstrability are rarely discussed in IS literature [59]. 


\section{CONCLUSIONS}

This study purposefully integrated a statistical inferential analysis with opinion mining to acquire elaborated results. It is believed that this method of integration can serve as a foundational improvement to traditional studies that base the analysis on an inferential analysis or opinion mining only. The research model and hypotheses were developed by combining Rogers [57] and Moore and Benbasat [51]'s theories, which were extended by adding trust in the Internet. The results of this study show that all hypotheses were confirmed, and opinion mining elaborated on the explanation of results for the positive, negative, and neutral sentiments of Saher. To the researcher's knowledge, this study is one of the rare studies in the IS field that investigate trust in the provider of service as a dependent variable and consider it a center of focus. In addition, violation systems and their relation to other factors has not been sufficiently studied in the IS literature [1, 40, 55]. Factors studied as characteristics of technology (visibility and result demonstrability) have also been seldom utilized in recent IS literature $[34,38,39,50]$. The results indicate that all investigated technology characteristics in this study are relevant to violation systems, which include detection and payment systems. Decision makers should consider the factors studied to improve trust. Facilitating electronic means of payments, inquiries, and all other transactions that are related to traffic violations is necessary to improve trust in the provider of service. These electronic means must be developed in a method that is congruent with citizens' expectations, needs, and values with attention to the simplicity of the interface and usage. Also, awareness campaigns showing the positive results of Saher could be conducted. Standardized policies and practices regarding the visibility of violation detection methods would lead to improved trust in the provider of service. The security and privacy of users is essential since traffic violation detection, recording, and payment involve the disclosure of private information in which technological security is needed. One of the limitations of this study is that a longitudinal design was not applied in the first study that was analyzed using inferential statistics; however, the second study can be seen as applying longitudinal attributes since it considered citizens' opinions towards Saher in 6 and half months.

\section{REFERENCES}

[1] Abu-Shanab, E., Irani, Z., 2014. Antecedents of Trust in E-government Services: An empirical Test in Jordan. Transforming Government: People, Process and Policy 8, 480 - 499.

[2] Al-Hujran, O., Al-Debei, M.M., Chatfield, A., Migdadi, M., 2015. The imperative of influencing citizen attitude toward e-government adoption and use. Computers in Human Behavior 53, 189-203.

[3] Al-Khouri, A.M., 2014. Electronic Payments: Building the Case for a National Initiative. Advances in Social Sciences Research Journal 1, 195.

[4] Alanazi, F., Hussain, S., Mandil, A., Alamro, N., 2015. Towards an electronic national injury surveillance system in Saudi Arabia. Eastern Mediterranean Health Journal 21.

[5] Alghnam, S., Palta, M., Hamedani, A., Alkelya, M., Remington, P.L., Durkin, M.S., 2014. Predicting inhospital death among patients injured in traffic crashes in Saudi Arabia. Injury 45, 1693-1699.
[6] Alhindi, W.A., Albawardy, F.A., 2013. Applying Change Management to Improving the Perception of the Speed Control System as Viewed by Drivers in the Kingdom of Saudi Arabia. Life Science Journal 10, 171-179.

[7] Almarabeh, T., AbuAli, A., 2010. A general framework for e-government: definition maturity challenges, opportunities, and success. European Journal of Scientific Research 39, 29-42.

[8] Almutairi , S.M., 2011. M-Government: Challenges and Key Success Factors - Saudi Arabia Case Study, in: Almutairi , S.M., Lawan Ahmed, M. (Eds.), Cases on ICT Utilization, Practice and Solutions: Tools for Managing Day-to-Day Issues. IGI Global, Hershey, PA, USA, pp. 78-96.

[9] Alsaghier, H., Ford, M., Nguyen, A., Hexel, R., 2010. Factors Affecting the Citizens' Trust in E-Government, in: Ajeeli, A.T., Al-Bastaki, Y. (Eds.), Handbook of Research on E-Services in the Public Sector: EGovernment Strategies and Advancements. IGI Global, Hershey, USA.

[10] Amagoh, F., 2015. Determinants of e-government diffusion in Nigeria An examination of theoretical models. Information Development, 1-18.

[11] Bagozzi, R.P., 2011. Measurement and Meaning in Information Systems and Organizational Research: Methodological and Philosophical Foundations. MIS Quarterly 35, 261-292.

[12] Bamasak, O., Al-Mehmadi, G., Al-Ghamdi, A., AlMutawa, A., Al-Ghamdi, M., Monitored Intelligent Car Speed Adaptation (MISA) System. International Journal of Electrical \& Computer Sciences IJECS-IJENS 11.

[13] Barney, J.B., Hansen, M.H., 1994. Trustworthiness as a source of competitive advantage. Strategic management journal 15, 175-190.

[14] Bart, Y., Shankar, V., Sultan, F., Urban, G.L., 2005. Are the drivers and role of online trust the same for all web sites and consumers? A large-scale exploratory empirical study. Journal of marketing 69, 133-152.

[15] Beldad, A., van der Geest, T., de Jong, M., Steehouder, M., 2012. A cue or two and I'll trust you: Determinants of trust in government organizations in terms of their processing and usage of citizens' personal information disclosed online. Government information quarterly 29 , 41-49.

[16] Bollen, K.A., 1989. Structural equations with latent variables. John Wiley \& Sons, New York, NY.

[17] Byrne, B.M., 2010. Structural equation modeling with AMOS: Basic concepts, applications, and programming, 2nd ed. Taylor \& Francis Group, New York.

[18] Carter, L., Bélanger, F., 2004. The Influence of Perceived Characteristics of Innovating on eGovernment Adoption. Electronic Journal of eGovernment 2, 11-20.

[19] Carter, L., Bélanger, F., 2005. The utilization of egovernment services: citizen trust, innovation and acceptance factors. Information Systems Journal 15, 525 . 
[20] Converse, J.M., Presser, S., 1986. Survey questions: Handcrafting the standardized questionnaire. Sage, Newbury Park, CA.

[21] Corbitt, B.J., Thanasankit, T., Yi, H., 2003. Trust and ecommerce: a study of consumer perceptions. Electronic commerce research and applications 2, 203-215.

[22] Coulter, K.S., Coulter, R.A., 2002. Determinants of trust in a service provider: the moderating role of length of relationship. Journal of Services Marketing 16, 35-50.

[23] Creswell, J.W., 2009. Research Design: Qualitative, Quantitative, and Mixed Methods Approaches, 3rd ed. SAGE Publications, Thousand Oaks, CA.

[24] Curran, P.J., West, S.G., Finch, J.F., 1996. The robustness of test statistics to nonnormality and specification error in confirmatory factor analysis. Psychological Methods 1, 16-29.

[25] D'Ambra, J., Wilson, C.S., Akter, S., 2013. Application of the task-technology fit model to structure and evaluate the adoption of E-books by Academics. Journal of the American Society for Information Science and Technology 64, 48-64.

[26] Detlor, B., Hupfer, M.E., Ruhi, U., Zhao, L., 2013. Information quality and community municipal portal use. Government Information Quarterly 30, 23-32.

[27] El Bcheraoui, C., Basulaiman, M., Tuffaha, M., Daoud, F., Robinson, M., Jaber, S., Mikhitarian, S., Wilson, S., Memish, Z.A., Al Saeedi, M., 2014. Get a license, buckle up, and slow down: risky driving patterns among Saudis. Traffic injury prevention 16 .

[28] Forward, S.E., 2006. The intention to commit driving violations - A qualitative study. Transportation Research Part F: Traffic Psychology and Behaviour 9, 412-426.

[29] Gefen, D., Straub, D., Boudreau, M., 2000. Structural Equation Modeling and Regression: Guidelines for Research Practice. Communications of the AIS 4, 1-77.

[30] Haddad, S.H., Yousef, Z.M., Al-Azzam, S.S., AlDawood, A.S., Al-Zahrani, A.A., AlZamel, H.A., Tamim, H.M., Deeb, A.M., Arabi, Y.M., 2015. Profile, outcome and predictors of mortality of abdomino-pelvic trauma patients in a tertiary intensive care unit in Saudi Arabia. Injury 46, 94-99.

[31] Hair, J.F., Black, W., Babin, B., Anderson, R., 2010. Multivariate data analysis: A global perspective, 7th ed. Pearson, Upper Saddle River, NJ.

[32] Harridge-March, S., Grabner-Kräuter, S., Faullant, R., 2008. Consumer acceptance of internet banking: the influence of internet trust. International Journal of bank marketing 26, 483-504.

[33] Hung, S.Y., Chang, C.M., Yu, T.J., 2006. Determinants of user acceptance of the e-government services: The case of online tax filing and payment system. Government Information Quarterly 23, 97-122.

[34] Hwang, Y., Al-Arabiat, M., Shin, D.-H., 2015. Understanding technology acceptance in a mandatory environment: A literature review. Information Development.
[35] Iivari, J., 2015. Making Sense of the History of Information Systems Research 1975-1999: A View of Highly Cited Papers. Communications of the AIS 36, 25.

[36] Jan, Y., 2014. Drivers' Perception of Saher Traffic Monitoring System in Jeddah, Saudi Arabia. Western Kentucky University.

[37] Kapoor, K., Dwivedi, Y., Williams, M., 2014. Examining the role of three sets of innovation attributes for determining adoption of the interbank mobile payment service. Information Systems Frontiers, 1-18.

[38] Kapoor, K.K., Dwivedi, Y.K., Williams, M.D., 2014. Rogers' Innovation Adoption Attributes: A Systematic Review and Synthesis of Existing Research. Information Systems Management 31, 74-91.

[39] Kawaljeet Kaur, K., Yogesh, K.D., Michael, D.W., 2014. Innovation adoption attributes: a review and synthesis of research findingsnull. European Journal of Innovation Management 17, 327-348.

[40] Khalil, O.E.M., Nasrallah, A., 2014. The Adoption of the Traffic Violation E-payment System (TVEPS) of Kuwait. Electronic Journal of Knowledge Management $12,3-22$.

[41] Kline, R.B., 2010. Principles and practice of structural equation modeling, 3rd ed. The Guilford Press, New York.

[42] Kotler, P., 1997. Marketing Management: Analysis, Planning, and Control, 9th ed. Prentice-Hall, Englewood Cliffs, NJ.

[43] Kugler, M., Smolnik, S., Raeth, P., 2013. Determining the factors influencing enterprise social software usage: Development of a measurement instrument for empirical assessment, 46th Hawaii International Conference on System Sciences (HICSS). IEEE, Wailea, Maui, pp. 3635-3644.

[44] Kumar, K.N., Christopher, T., 2015. Opinion Mining: A Survey. International Journal of Computer Applications 113.

[45] Liao, C., Liu, C.-C., Chen, K., 2011. Examining the impact of privacy, trust and risk perceptions beyond monetary transactions: An integrated model. Electronic Commerce Research and Applications 10, 702-715.

[46] Liu, B., 2012. Sentiment analysis and opinion mining. Synthesis Lectures on Human Language Technologies 5, $1-167$.

[47] Mahmood, M., Osmani, M., Sivarajah, U., 2014. The Role of Trust in E-Government Adoption: A Systematic Literature Review, Twentieth Americas Conference on Information Systems, Savannah.

[48] Manakshe, A.R., Jirkar, S., Wakhare, P., Buram, V., 2014. Analysis of secure electronic transmission (SET) system for electronic transactions. International Journal of Research in Advent Technology 2, 12-15.

[49] Miller, A.H., Listhaug, O., 1990. Political parties and confidence in government: A comparison of Norway, Sweden and the United States. British Journal of Political Science 20, 357-386.

[50] Mohanad, H., 2015. Review of ICT Adoption Research in Arabic Countries: Trends and Future Research. 
Information Resources Management Journal (IRMJ) 28, $52-68$.

[51] Moore, G.C., Benbasat, I., 1991. Development of an instrument to measure the perceptions of adopting an information technology innovation. Information Systems Research 2, 192-222.

[52] Mou, J., Cohen, J., 2013. Trust and Risk in Consumer Acceptance of E-services: A Meta-analysis and a Test of Competing Models, Thirty Fourth International Conference on Information Systems, Milan.

[53] Mou, J., Cohen, J., 2014. Trust in electronic-service providers: A meta-analysis of antecedents, Proceedings of The 18th Pacific Asia Conference on Information Systems.

[54] Nedbal, D., Stieninger, M., Erskine, M., Wagner, G., 2014. The Adoption of Cloud Services in the Context of Organizations: An Examination of Drivers and Barriers, Twentieth Americas Conference on Information Systems, Savannah.

[55] Pearce, A.D.N., Rowley, P., 2012. Implementing ATVAM, the world's largest ITS program, across Saudi Arabia, IET and ITS Conference on Road Transport Information and Control, London, pp. 1-6.

[56] Rogers, E.M., 1983. Diffusion of Innovations, 3rd ed. Free Press, New York.

[57] Rogers, E.M., 2003. Diffusions of Innovations, 5th ed. Free Press, New York.

[58] Rotter, J.B., 1971. Generalized Expectations for Interpersonal Trust. American Psychologist 26, 443-452.

[59] Schmidt, M., Arnett, K., 2007. Synthesis and Analysis of Moore and Benbasat's PCI and Witte's Susceptibility and Severity of Threat Scales. AMCIS 2007 Proceedings, 196.
[60] Sharma, S.K., 2015. Adoption of e-government services: The role of service quality dimensions and demographic variables. Transforming Government: People, Process and Policy 9, 207-222.

[61] Smith, M.A., Himelboim, I., Rainie, L., Shneiderman, B., 2015. The Structures of Twitter Crowds and Conversations, in: Matei, S.A., Russell, M.G., Bertino, E. (Eds.), Transparency in Social Media. Springer, pp. 67108.

[62] Thelwall, M., Buckley, K., Paltoglou, G., 2011. Sentiment in Twitter events. Journal of the American Society for Information Science and Technology 62, 406-418.

[63] Thompson, R.L., Higgins, C.A., Howell, J.M., 1991. Personal computing: Towards a conceptual model of utilization. MIS Quarterly 15, 125-143.

[64] Tolbert, C.J., Mossberger, K., 2006. The Effects of E-Government on Trust and Confidence in Government. Public Administration Review 66, 354-369.

[65] Tornatzky, L.G., Klein, K.J., 1982. Innovation characteristics and innovation adoption-implementation: A meta-analysis of findings. Engineering Management, IEEE Transactions on, 28-45.

[66] Warkentin, M., Gefen, D., Pavlou, P., Rose, G., 2002. Encouraging Citizen Adoption of e-Government by Building Trust. Electronic Markets 12, 157-162.

[67] Wright, K.B., 2005. Researching Internet-based populations: Advantages and disadvantages of online survey research, online questionnaire authoring software packages, and web survey services. Journal of Computer-Mediated Communication 10. 